\title{
DESIGN OF PARTICULATE MATERIAL COMPACTOR ROLLS DIAMETER
}

\author{
Peter Peciar*, Oliver Macho, Maroš Eckert, Roman Fekete, \\ Peter Kotora, Martin Juriga, Juraj Kabát, Ludmila Gabrišová, \\ MARIÁN PECIAR
}

\author{
Slovak University of Technology in Bratislava, Faculty of Mechanical Engineering, Institute of Process \\ Engineering, Námestie Slobody 17, 812 31, Bratislava, Slovakia \\ * corresponding author: peter.peciar@stuba.sk
}

\begin{abstract}
At present, in a period of an industrial expansion great emphasis is placed on the environment. That means aiming for a reduced energy consumption, and also lessening dustiness from very fine powder material. This category also includes particulate material agglomeration processes. Because this process is very energy-intensive, it is necessary to correctly design these devices. The aim of this paper is to focus on a theoretical design of a production compactor with the rolls diameter for an experimental particulate material, based on Johanson's theory and experimentally measured material properties. The material used for experimental measurements was an NPK-based industrial fertilizer consisting of several components. The results of this paper is the dependence of the ratio of the maximum compression pressure to the initial compression pressure from the rolls diameter of the proposed compactor.
\end{abstract}

KEYWORDS: particulate material; compaction; compactor; rolls diameter; experimental measurements; fertilizer.

\section{INTRODUCTION}

Studying the behaviour of particular materials during handling and processing is quite difficult. In contrast to purely solid, liquid or gaseous state substances, their properties as a three-phase system are influenced by various factors. Agglomeration of a particulate material significantly enhances the bonds between the particles forming the material to such an extent that a smaller number of larger solids is created. Thus, new particulate materials are produced - for example, pellets, briquettes, tablets, granules, etc., whose geometrical properties differ greatly from the geometric properties of the original substance. Compacting is one of operations most used for industrial applications of powder processing technologies. Its essence lies in feeding the particulate substance between the rolls from the feeder, either by gravity force or forced filling, and its subsequent compaction by mechanical pressure with an exponential course.

\section{THEORY OF COMPACTION}

J.R. Johanson is one of the most acknowledged authors in the particulate material compaction field. In his publications [1 6], he deals with the compactor design, air and liquid phase problems in the pores of a particulate material, and also process improvements for a compacting and briquetting. The mathematical model proposed by Johanson shows the relationship between material properties, operating conditions in the compactor, and compactor dimensions (assuming that the temperature and pressure required for com- paction are known from previous studies). Johanson's mathematical model answers the question of what are the dimensions of the compactor and the force between the rolls necessary to achieve the necessary pressure for a material at a given temperature. It is assumed that the material is isotropic, compressible, and also that it behaves according to the effective flow function as proposed by Jenike and Schield [7].

It was Johansson who described the compaction of a particulate material through a two-roll compactor by the so-called nip angle $\alpha_{N}$. This angle separates the slip area and the area of compression. In the slip area, in the zone over the nip angle, mutual movement occurs between the surface and the material. The material is acted on by its own weight or by the force effect of the screw forced feeding and to a small extent, by the shear stress from the rolls through which the material is dragged into the area between the rolls. In this zone, the particles of the material change position and displacement of a substantial part of the air contained in the material occurs there. In the area of the pressing zone under the nip angle,the material on the surface of the rolls moves at the same speed as the surface speed of the rolls. The effects of wall friction are gradually reduced, and, on the contrary, the normal components of the stress from the rolls begin to work. In this area, the particles of the material deform and the material becomes compact [8, 9].

For the zone over the nip angle, it is possible to calculate the pressure conditions by means of the bulk material mechanics. For the zone under the nip angle, pressure ratios are derived from the strain curve. 


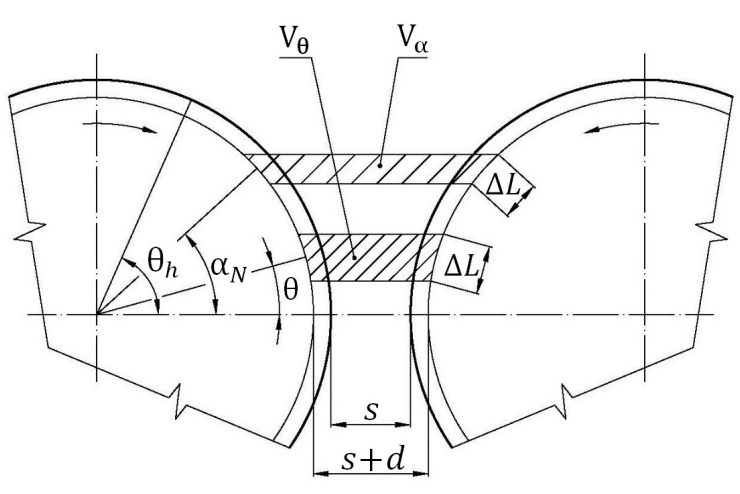

Figure 1. Nip zone. [1]

Stress distribution between the rolls above the nip angle can be calculated by combining the equations of the particulate material balance element and the limit state equation, provided that the boundary conditions are given by [8, 10] and, in the case of stress distribution under the nip angle, the volume strain dependency can be applied.

\subsection{Distribution of Stress Gradient OVER THE NIP ANGLE}

In the study of an isolated element of a particulate material, when expressing the balance of forces acting on the selected element in the $x$-direction, the following applies:

$$
\begin{aligned}
&\left(\sigma_{x}+\right.\left.\frac{\partial \sigma_{x}}{\partial x} \mathrm{~d} x\right) \mathrm{d} y \mathrm{~d} z-\sigma_{x} \mathrm{~d} y \mathrm{~d} z \\
&+\left(\tau_{y x}+\frac{\partial \tau_{y x}}{\partial y} \mathrm{~d} y\right) \mathrm{d} z \mathrm{~d} x-\tau_{y x} \mathrm{~d} z \mathrm{~d} x \\
&+\left(\tau_{z x}+\frac{\partial \tau_{z x}}{\partial z} \mathrm{~d} z\right) \mathrm{d} y \mathrm{~d} x-\tau_{z x} \mathrm{~d} y \mathrm{~d} x \\
&+X \mathrm{~d} x \mathrm{~d} y \mathrm{~d} z=0 .
\end{aligned}
$$

Similarly, it is possible to write the forces balances in $y$-direction and $z$-direction. By modifying these equations for planar stress (not considering the equation in the z-direction) we get an equation

$$
\begin{aligned}
& \frac{\partial \sigma_{x}}{\partial x}+\frac{\partial \tau_{y x}}{\partial y}+X=0, \\
& \frac{\partial \sigma_{y}}{\partial y}+\frac{\partial \tau_{x y}}{\partial x}+Y=0,
\end{aligned}
$$

where $X$ and $Y$ represent the volume forces, $\tau_{i, j}$ is the shear stress in the plane of $i, j, \sigma_{x}$ is the stress in the plane $x$ and $\sigma_{y}$ is the stress in the plane $y$.

The equilibrium limit state equation or the plasticity equation for non-cohesive and semi-cohesive substances can be expressed from the overlap defined by Mohr's circle, where each of the main stresses and slip line directions are related to the selected rectangular coordinate system $x$ and $y$, where $\sigma$ is the stress in the particular material, $\gamma$ is the angle between the $x$-axis and the slip line, and $\sigma_{c}$ is the cohesion of the material:

$$
\begin{gathered}
\sigma_{x}=\sigma[1+\sin \delta \sin (2 \gamma+\delta)]-\sigma_{c}, \\
\sigma_{y}=\sigma[1-\sin \delta \sin (2 \gamma+\delta)]-\sigma_{c}, \\
\tau_{x y}=-\sigma \sin \delta \cos (2 \gamma+\delta) .
\end{gathered}
$$

By substituting (3)-(5) into (1)-(2), provided that the volume force in the $y$-axis is, $Y=\kappa$, an assembly of the two linear differential equations of first order with unknown $\sigma(x, y)$ and $\gamma(x, y)$, is obtained, while $\kappa$ represents the weight of the material. By the introduction of the vectors $X(x, y), U(\sigma, \gamma), F(0, \kappa)$ and the matrices

$$
\begin{gathered}
A=\left(\begin{array}{cc}
1+\sin \delta \sin (2 \gamma+\delta) & 2 \sigma \sin \delta \cos (2 \gamma+\delta) \\
-\sin \delta \cos (2 \gamma+\delta) & -2 \sigma \sin \delta \sin (2 \gamma+\delta)
\end{array}\right), \\
B=\left(\begin{array}{cc}
-\sin \delta \cos (2 \gamma+\delta) & 2 \sigma \sin \delta \sin (2 \gamma+\delta) \\
1+\sin \delta \sin (2 \gamma+\delta) & -2 \sigma \sin \delta \cos (2 \gamma+\delta)
\end{array}\right),
\end{gathered}
$$

the system of equations can be written in the form.

$$
A \frac{\partial U}{\partial x}+B \frac{\partial U}{\partial y}=F
$$

The solution of this hyperbolic equation, provided that the effect of its own weight $(\kappa=0)$ is ignored, the relation for the distribution of the pressure gradient over the nip angle is obtained:

$$
\begin{aligned}
\frac{\mathrm{d} \sigma_{\theta}}{\mathrm{d} \theta} & =\frac{-4 \sigma_{\theta}\left(\frac{\pi}{2}-\theta-\lambda\right) \tan \delta \cos \theta}{1+\frac{s}{D}-\cos \theta} \\
& \times \frac{1}{\cot \left(\frac{\pi}{\frac{2}{2}+\theta+\lambda}-\nu\right)-\cot \left(\frac{\frac{\pi}{2}+\theta+\lambda}{2}+\left(\frac{\pi}{4}-\frac{\gamma}{2}\right)\right)} .
\end{aligned}
$$

Here, $\sigma_{\theta}$ is the stress between the rolls at an angle $\theta$. The solution procedure is given in [10, 11].

\subsection{Distribution of Stress GRADient UNDER THE NIP ANGLE}

To describe the distribution of the stress gradient under the nip angle, Johanson used uniaxial compressibility in an oedometer.

This is based on the idea that under the nip angle there is no mutual movement between the material and the drum surface. This means that if the volume that is bounded by the side arches $\Delta L$ is collected and compressed to volume $V_{\theta}$, it must again be bounded by the arc segments $\Delta L$. The Johanson equation for the compactor has the following form:

$$
\frac{\sigma_{\theta}}{\sigma_{m}}=\left(\frac{\rho_{\theta}}{\rho_{m}}\right)^{K}=\left(\frac{V_{m}}{V_{\theta}}\right)^{K}
$$

This relationship can be modified by the expression of the relationships

$$
\begin{gathered}
V_{m}=(s+D) \Delta L B, \\
V_{\theta}=(s+D(\cos \theta)) \cos \theta B \Delta L+B d \Delta L= \\
=(d+(s+D(1-\cos \theta)) \cos \theta) \Delta L B .
\end{gathered}
$$




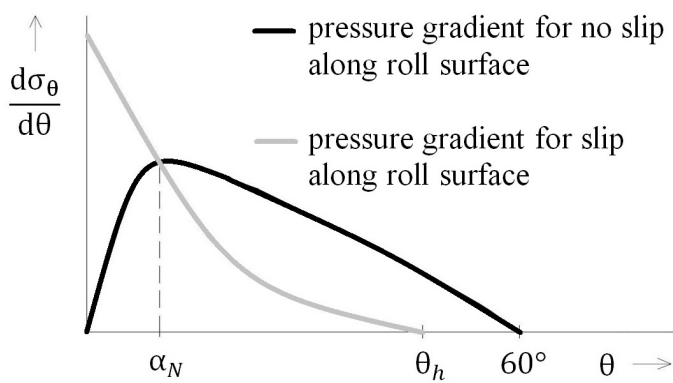

FiguRE 2. Determination of nip angle - course of stress gradient over and under the nip angle 8 .

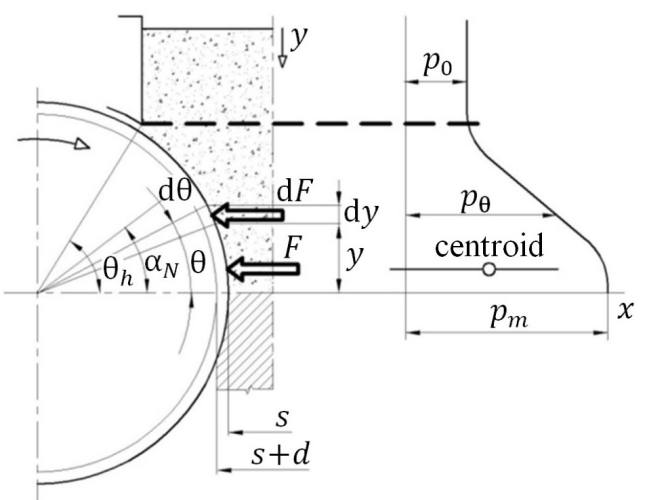

FiguRE 3. Forces balance in the compression zone of the compacting process [11.

When calculating the nip angle, it is necessary to know the ratio $\frac{\mathrm{d} \sigma_{\theta}}{\mathrm{d} \theta}$, so the adjusted equation is derived according to $\mathrm{d} \theta$ and it gives the following relationship for stress distribution under the nip angle:

$$
\frac{\mathrm{d} \sigma_{\theta}}{\mathrm{d} \theta}=\frac{-K \sigma_{\theta}\left(2 \cos \theta-1-\frac{s}{D}\right) \sin \theta}{\frac{s}{D}+\left(1+\frac{s}{D}-\cos \theta\right) \cos \theta}
$$

It should be noted that compressibility, as the material property of the particulate material, depends on many factors, e.g. properties of the particulate material, speed of compression, oedometer type, the amount of sample in the oedometer and other things. The Johanson equation showed that the given relation (6) is not suitable for all types of materials. The solution to this problem can be found in [10, 11, where the term "volume strain module", which should be parallel to the modulus of elasticity for solids, was introduced.

Thus, if we know the pressure distribution between the compactor rolls, we can calculate the total spanning force according to the relation

$$
F=\int_{\theta=0}^{\theta=\theta_{h}} p_{\theta} B \mathrm{~d} y=\int_{0}^{\theta_{h}} p_{\theta} \frac{B D}{2} \cos \theta \mathrm{d} \theta,
$$

where $p_{\theta}=\sigma_{\theta}(1+\sin \delta)$ is the horizontal pressure on the axis between the compactor rolls. The equation does not exactly describe the reality.
This state is due to the suspension of the compacted material. Further adjustments to the equation will result in the form

$$
F=p_{m} \frac{B D}{2} X_{F},
$$

where $p_{m}$ is the maximum horizontal pressure caused by the action of the rolls on the material at $\theta=0$, and the force factor $X_{F}$ is defined as

$$
X_{F}=\int_{0}^{\alpha_{N}}\left(\frac{\frac{d+s}{D}}{\frac{d}{D}+\left(1+\frac{s}{D}-\cos \theta\right) \cos \theta}\right)^{K} \cos \theta \mathrm{d} \theta .
$$

In the same way, we can calculate the torque on the compactor roll

$$
M_{K}=p_{m} \frac{B D}{8} Y_{M}
$$

where

$Y_{M}=\int_{0}^{\alpha_{N}}\left(\frac{\frac{d+s}{D}}{\frac{d}{D}+\left(1+\frac{s}{D}-\cos \theta\right) \cos \theta}\right)^{K} \sin 2 \theta \mathrm{d} \theta$.

In order to be able to calculate the total span force $F$ and the torque $M_{k}$, we must know the geometric dimensions $\frac{s}{D}, \frac{d}{D}, B$, compression coefficient $K$, nip angle $\alpha_{N}$ and maximum horizontal pressure $p_{m}$.

When the rolls are rotated in the compactor, the inlet pressure $p_{0}$ increases to the maximum horizontal pressure $p_{m}$ at the narrowest gap between the rolls. This pressure is important because it expresses how the substance will be compacted. The relationship for the mechanical amplification can be deduced from the function of the effective flow, and we get

$\frac{p_{m}}{p_{0}}=R_{1} \frac{1+\sin \delta}{1-\sin \delta}\left(\frac{\frac{d}{D}+\left(1+\frac{s}{D}-\cos \alpha_{N}\right) \cos \alpha_{N}}{\frac{d+s}{D}}\right)^{K}$,

where

$$
\begin{aligned}
R_{1}= & \exp \int_{\theta_{h}}^{\alpha_{N}} \frac{4\left(\frac{\pi}{2}-\theta-\lambda\right) \tan \delta}{1+\frac{s}{D}-\cos \theta} \\
& \times \frac{1}{\cot (A-\nu)-\cot (A+\nu)} \cos \theta \mathrm{d} \theta, \\
p_{m}= & \sigma_{m}(1+\sin \delta), \\
p_{0}= & \sigma_{0}(1-\sin \delta) .
\end{aligned}
$$

The relation for calculating the diameter of rolls $D$ is obtained by adjusting the equation for the mechanical pressure boosting

$$
D=\frac{(d+s)\left(\frac{p_{m}}{R_{1} p_{0}} \frac{1-\sin \delta}{1+\sin \delta}\right)^{1 / K}-d-s \cos \alpha_{N}}{\left(1-\cos \alpha_{N}\right) \cos \alpha_{N}} .
$$

The nip angle can be calculated according to the relationship 12

$$
\alpha_{N}=\arccos \left(1-\frac{s}{D}\left(\frac{\rho}{\rho_{1}}-1\right)\right) .
$$




\begin{tabular}{lll}
\hline Ammonium sulphate & $\left(\mathrm{NH}_{4}\right)_{2} \mathrm{SO}_{4}$ & Fig. 4a \\
\hline Potassium sulphate & $\mathrm{K}_{2} \mathrm{SO}_{4}$ & Fig. $4 \mathrm{p}$ \\
\hline Potassium chloride & $\mathrm{KCl}$ & Fig. 45 \\
\hline Magnesium sulphate & $\mathrm{MgSO}_{4}$ & Fig. 4d \\
\hline Diammonium phosphate & $\left(\mathrm{NH}_{4}\right)_{2} \mathrm{HPO}_{4}$ & Fig. 4p \\
\hline Urea & $\mathrm{CON}_{2} \mathrm{H}_{4}$ & Fig. 4f \\
\hline
\end{tabular}

TABLE 1. Feed materials.

\begin{tabular}{ll}
\hline Ammonium sulphate & $1.61 \mathrm{~mm}$ \\
\hline Potassium sulphate & $3.72 \mathrm{~mm}$ \\
\hline Potassium chloride & $4.00 \mathrm{~mm}$ \\
\hline Magnesium sulphate & $3.94 \mathrm{~mm}$ \\
\hline Diammonium phosphate & $3.85 \mathrm{~mm}$ \\
\hline Urea & $2.23 \mathrm{~mm}$ \\
\hline
\end{tabular}

TABle 2. Characteristic dimensions Dv(50).

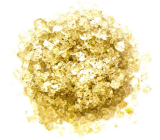

a)

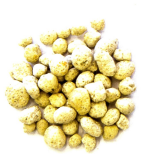

d)

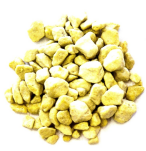

b)

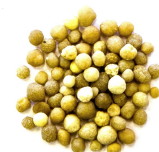

e)

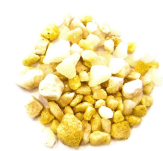

c)

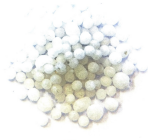

f)
Figure 4. Feed materials: a) Ammonium sulphate, b) Potassium sulphate, c) Potassium chloride, d) Magnesium sulphate, e) Diammonium phosphate, f) Urea.

\section{EXPERIMENTAL PART}

\subsection{Feed materials}

The material used for experimental measurements was an NPK-based industrial fertilizer consisting of the raw materials listed in Table 1

Due to the size of the particles, the distribution characteristic of the feed materials produced was, performed on a Microtrac PartAn 3D (Fig. 5 ) analyser of the picture of the particles. The particles falling from the vibration hopper were recorded by a highspeed camera, which took pictures of the motion of the falling particles. On the basis of the series of pictures, a complete $3 \mathrm{D}$ picture of the individual agglomerates was prepared and, as on the basis of their volume, the consequent cumulative distribution characteristic was done. The characteristics dimensions $\operatorname{Dv}(50)$ from analysis of the feed materials are stated in Table 2

\begin{tabular}{lc}
\hline Bulk density & $1001.8 \mathrm{~kg} \mathrm{~m}^{-3}$ \\
\hline Angle of internal friction & $43.3^{\circ}$ \\
\hline Effective angle of internal friction & $50.5^{\circ}$ \\
\hline Angle of wall friction & $25.2^{\circ}$ \\
\hline Johanson's compressibility factor & 11.26 \\
\hline
\end{tabular}

TABLE 3. Properties of experimental material

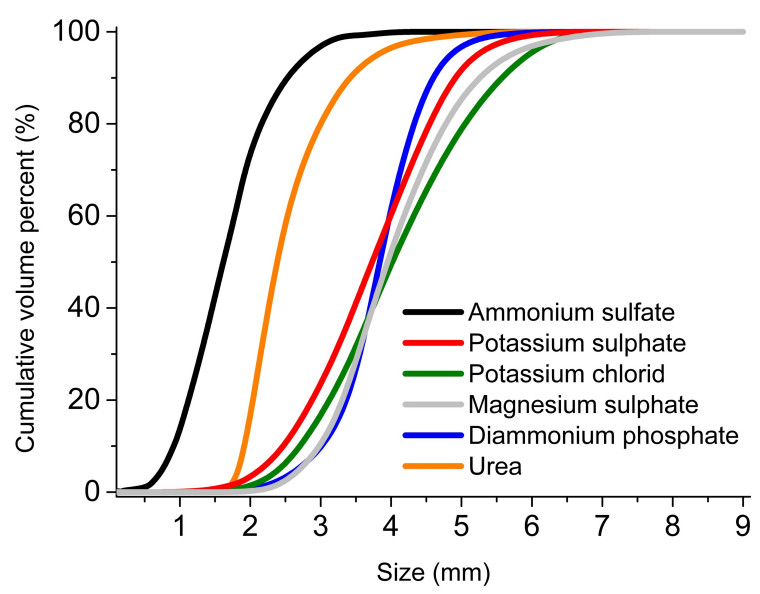

FiguRE 5. Distribution characteristic of feed materils measured on Microtrac PartAn 3D Equiplment.

\subsection{PRocess OF MIXING AND MILLING OF FEED MATERIALS}

Before the compacting process itself, it was necessary to mix the feed materials at a given ratio and to grind them to the desired fraction. Milling the mixed mixture was done on a conical mill.

\subsection{EXPERIMENTAL MATERIAL}

The experimental material (Fig. 6) was treated with a ground mixture consisting of feed materials (Fig. 44). The experimental material was used to determine the mechanical and physical properties necessary to correctly design the diameter of the compactor rolls. The measured properties of the experimental material are shown in Table 3

The Malvern Mastersizer 3000 was used to measure the distribution characteristics of the experimental material [13 15]. The distribution characteristics of the experimental material are shown in Figure 7 .

The Freeman Technology FT4 [16-19] was used to measure the flow properties of the experimental material. The measurement of the internal and wall friction angles is shown in Figures 8 and 9 and the resulting values are shown in Table 3 .

Before the actual process of compacting, it was necessary to verify the compatibility of the test material in an oedometer, on an experimental KISTLER press. The course of the single-axis compressibility test is shown in Figure 10, while a modified version, which adds a logarithm of the stress ratio $\ln \frac{\sigma}{\sigma_{0}}$ and a logaritm of densities ratio $\ln \frac{\rho}{\rho_{0}}$ to the dependency by the 


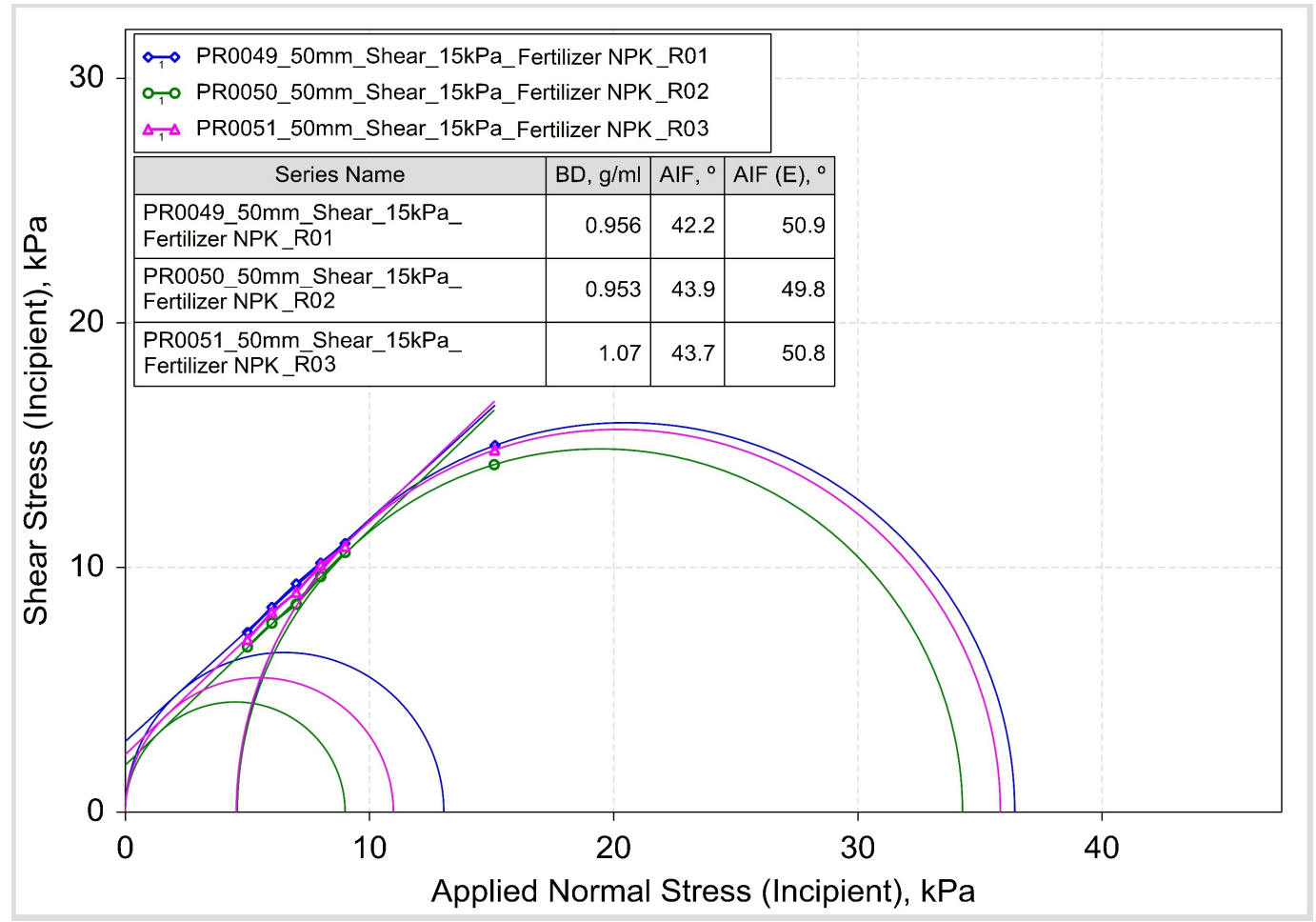

FIGURE 8. Internal friction angle of experimental material measured on Freeman Technology FT4.

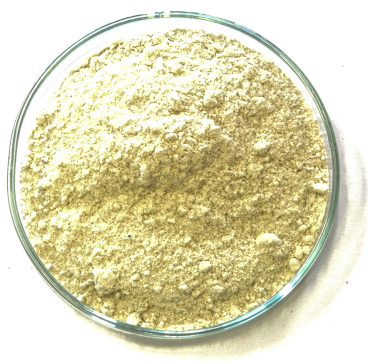

FiguRE 6. Experimental material.

following equation, is shown in Figure 11]12]:

$$
\ln \frac{\sigma}{\sigma_{0}}=K \ln \frac{\rho}{\rho_{0}}
$$

By means of this modification, it was possible to assess the behaviour of the test material during the single-axis compaction, wherein this material behaved accordingly to the compaction theory in line with Johanson; by means of a mathematical analysis, a compressibility factor of 11.26 was found. The test material is well-compressible and suitable for a compaction in a roll compactor.

If the compressibility factor is equal to the value of 1 , the compressibility of the sample is linear throughout the whole course of the compaction of the samples. The higher the factor, the less linear is the compressibility of the sample throughout the course. If the value of the compression force does not sufficiently exceed the required value, the sufficient sample compression does not occur. Although an exact definition

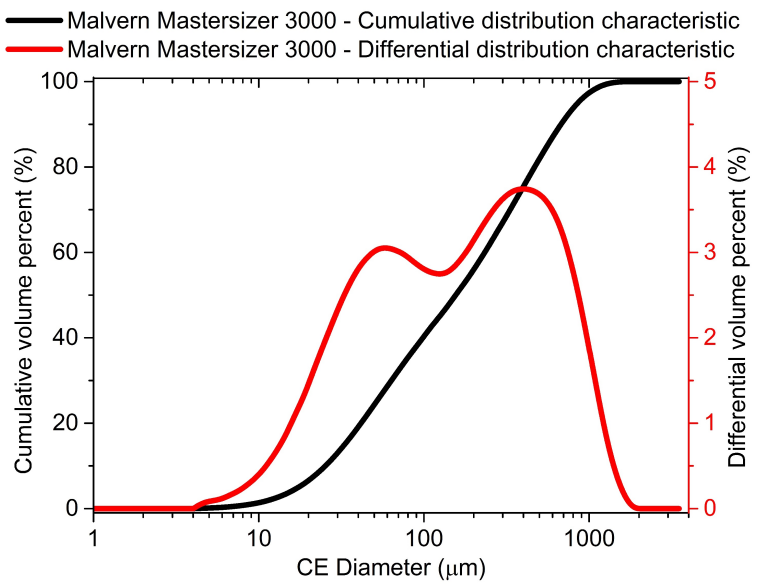

FIGURE 7. Distribution characteristics of experimental material measured on Malvern Mastersizer 3000 equipment.

of the Johanson compressibility factor is not possible, the higher this number is (tens, hundreds), the more problematic is the compaction process [12].

\subsection{EXPERIMENTAL COMPACTOR}

A laboratory compactor of a special design was used for the experimental measurements and was designed and constructed at the Institute of Process Engineering of Faculty of Mechanical Engineering of Slovak University of Technology in Bratislava. The geometric dimensions of the laboratory compactor are shown in Table 4 


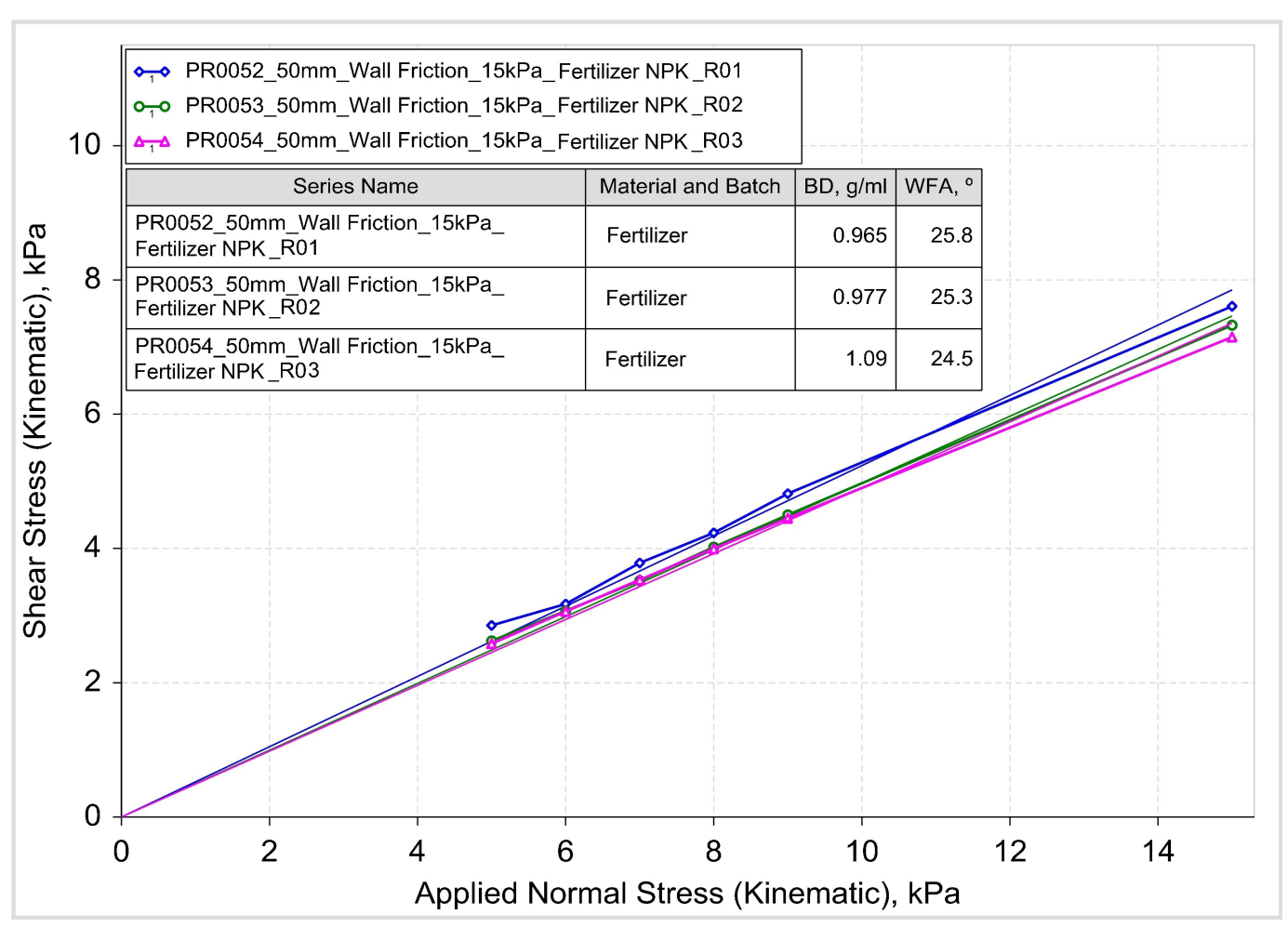

Figure 9. Wall friction angle of experimental material measured on Freeman Technology FT4.

\begin{tabular}{lc}
\hline Diameter of laboratory compactor rolls & $0.26 \mathrm{~m}$ \\
\hline Width of laboratory compactor rolls & $0.07 \mathrm{~m}$ \\
\hline Gap between laboratory compactor rolls & $0.001 \mathrm{~m}$ \\
\hline Rotary frequency of laboratory compactor rolls & max. $13.5 \mathrm{rpm}$ \\
\hline Rotary frequency of the screw of laboratory compactor & max. $10.0 \mathrm{rpm}$ \\
\hline
\end{tabular}

TABLE 4. Geometric dimensions of the laboratory compactor

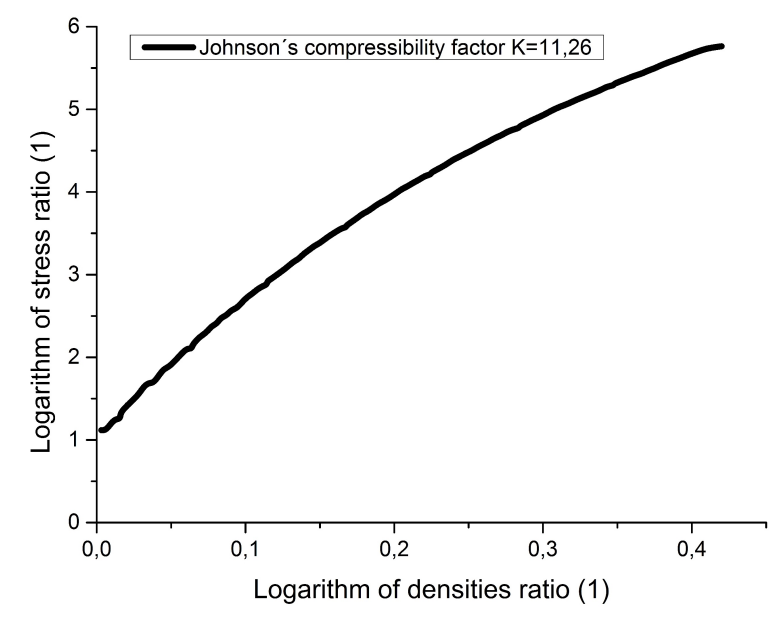

Figure 10. Course of single-axis compactibility test.

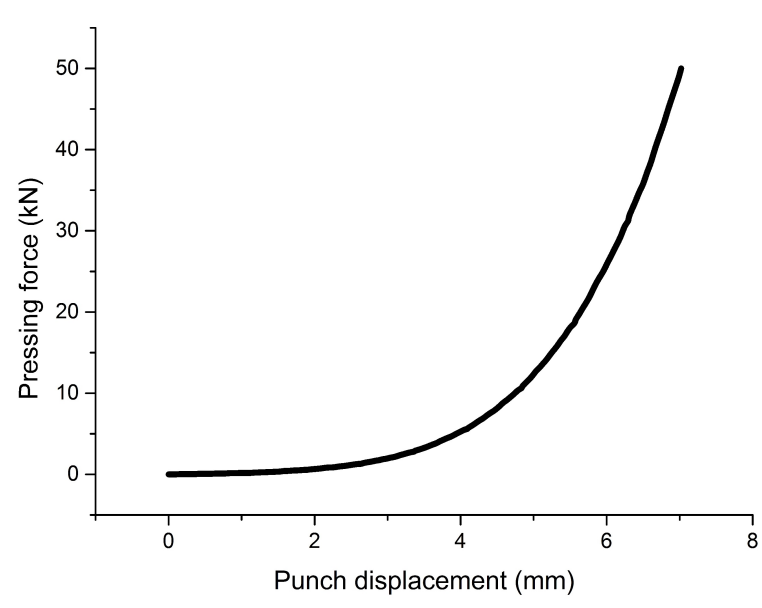

FIGURE 11. Course of single-axis compactibility test according to Johanson. 


\begin{tabular}{lc}
\hline Bulk density of experimental material & $1001.8 \mathrm{~kg} \mathrm{~m}^{-3}$ \\
\hline Density of compacts & $1650.0 \mathrm{~kg} \mathrm{~m}^{-3}$ \\
\hline Johanson's compressibility factor & 11.26 \\
\hline Diameter of laboratory compactor rolls & $0.26 \mathrm{~m}$ \\
\hline Width of laboratory compactor rolls & $0.07 \mathrm{~m}$ \\
\hline Gap between laboratory compactor rolls & $0.001 \mathrm{~m}$ \\
\hline Angle of internal friction & $43.3^{\circ}$ \\
\hline Effective angle of internal friction & $50.5^{\circ}$ \\
\hline Angle of wall friction & $25.2^{\circ}$ \\
\hline Nip angle (wegde angle) & $5.62^{\circ}$ \\
\hline Maximum compression pressure & $124101000 \mathrm{~Pa}$ \\
\hline Initial compression pressure & $19634 \mathrm{~Pa}$ \\
\hline
\end{tabular}

TABLE 5. Input data for first iteration

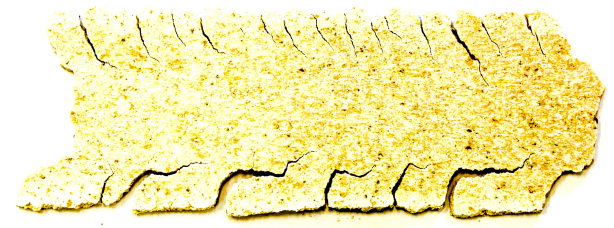

Figure 12. Compacted strip.

\subsection{EXPERIMENTAL MEASUREMENTS}

Experimental measurements were made at different rotary frequencies of the compactor rolls and different rotary frequencies of the forced feeding screw in order to find the most ideal compacts in terms of strength. Figure 12 shows a compacted strip.

The target product was a sample with the following compacting process settings: rotary frequency of laboratory compactor rolls $5.4 \mathrm{rpm}$; rotary frequency of the screw of forced feeding of the laboratory compactor $3 \mathrm{rpm}$.

The bulk density of the compact was $1650.0 \mathrm{~kg} \mathrm{~m}^{-3}$.

The nip angle (wedge angle) of the experimental material for the selected compaction process parameters on the laboratory compactor was calculated according to relation (9) and had a value of $5.62^{\circ}$.

The total compression force was recorded in the laboratory compass measurements, from which the maximum compression pressure was calculated. The average value of the pressing force $F_{\mathrm{EXP}}$ was $11045 \mathrm{kN}$ and the average maximum pressing pressure was $p_{m \mathrm{EXP}}=124.101 \mathrm{MPa}$.

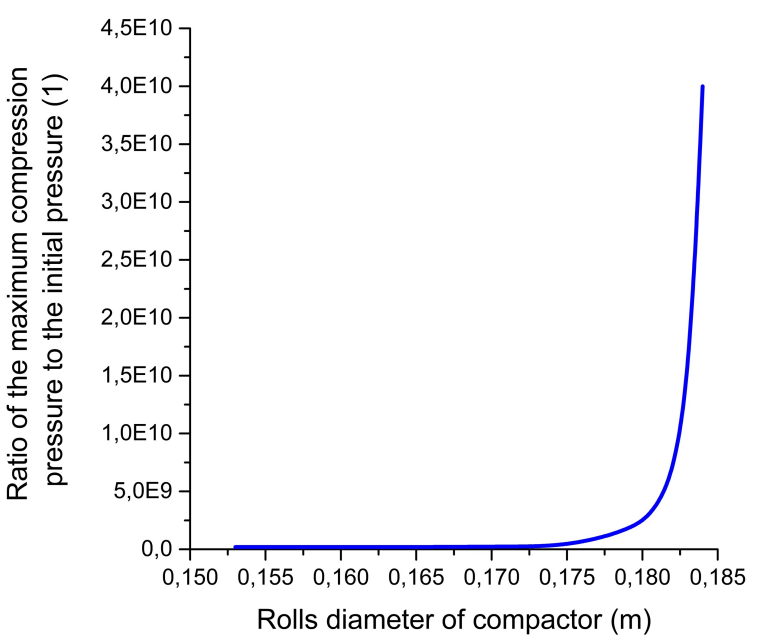

FiguRE 13. Ratio of the maximum compression pressure to the initial compression pressure from the rolls diameter of the proposed compactor.

\section{Results}

Calculation of the minimal diameter of the rolls for the proposed compactor is performed by iterations of equations (7) and (8); the input data for the first iteration being is given in Table 5

The result of the iterations is the dependence $\frac{p_{m}}{p_{0}}=f(D)$ (Fig. 13), the ratio of the maximum compression pressure to the initial compression pressure from the rolls diameter of the proposed compactor.

\section{CONClusion}

To determine the rolls diameter of the proposed compactor, it is necessary to correctly estimate the initial compression pressure $p_{0}$, which will depend on the geometric dimensions of the hopper of the proposed compactor. However, in Figure 13 it is observable that the function has an exponential course, with the 
rolls diameter of the proposed production compactor not reaching $0.185 \mathrm{~m}$, so that the proposed diameter is also able to compensate for the local maximum pressure extremes $p_{m}$ between the rolls of the compactor.

This method of designing the compactor roll could be used in the design of processing technology not only for fertilizers but also for other applications of the compacting of a particulate material (for example, dust from production of brake linings [12, 20, following the elimination of the problems in this area [21, 22]).

\section{LIST OF SYMBOLS}

$\alpha_{N} \quad$ Nip angle (wedge angle) $\left[^{\circ}\right]$

$\gamma$ Angle between the $x$-axis and the slip line $\left[^{\circ}\right]$

$\delta \quad$ Effective angle of internal friction $\left[^{\circ}\right]$

$\kappa$ Weight of the material $[\mathrm{N}]$

$\lambda$ Angle between direction of $\sigma_{1}$ and tangent to roll surface $\left[^{\circ}\right]$

$\rho \quad$ Bulk density $\left[\mathrm{kg} \mathrm{m}^{-3}\right]$

$\rho_{\theta} \quad$ Bulk density at an angle $\theta\left[\mathrm{kg} \mathrm{m}^{-3}\right]$

$\rho_{\mathrm{o}} \quad$ Initial bulk density $\left[\mathrm{kg} \mathrm{m}^{-3}\right]$

$\rho_{1} \quad$ Material density $\left[\mathrm{kg} \mathrm{m}^{-3}\right]$

$\rho_{m} \quad$ Bulk density at $\theta\left[\mathrm{kg} \mathrm{m}^{-3}\right]$

$\sigma$ Normal stress $[\mathrm{Pa}]$

$\sigma_{\theta}$ Stress between the rolls at an angle $\theta[\mathrm{Pa}]$

$\sigma_{\mathrm{o}}$ Initial normal stress $[\mathrm{Pa}]$

$\sigma_{1} \quad$ Major principall stress $[\mathrm{Pa}]$

$\sigma_{c}$ Cohesion of the material $[\mathrm{Pa}]$

$\sigma_{m}$ Maximal stress between the rolls [Pa]

$\sigma_{x} \quad$ Normal stress in the plane $x[\mathrm{~Pa}]$

$\sigma_{y} \quad$ Normal stress in the plane $y[\mathrm{~Pa}]$

$\tau_{i, j} \quad$ Shear stress in the plane of $i, j \quad[\mathrm{~Pa}]$

$\theta \quad$ Angular position in roll bite $\left[^{\circ}\right]$

$\theta_{h}$ Angular position at which feed pressure $p_{0}$ is applied $\left[^{\circ}\right]$

$\nu$ Angle $\frac{\pi}{4}-\frac{\delta}{2}\left[^{\circ}\right]$

$\Delta L$ Arc segments $[\mathrm{m}]$

$d$ Depth of grooves on the compactor rolls [m]

$p_{\theta} \quad$ Horizontal pressure on the axis between the compactor rolls $[\mathrm{Pa}]$

$p_{\mathrm{o}} \quad$ Inlet compression pressure $[\mathrm{Pa}]$

$p_{m}$ Maximum compression pressure $[\mathrm{Pa}]$

$p_{m \text { EXP }}$ Average maximum pressing pressure $[\mathrm{Pa}]$

$s \quad$ Gap between the rolls [m]

$B$ Width of the compactor rolls [m]

$D$ Diameter of the compactor rolls [m]

$F \quad$ Pressing force [N]

$F_{\text {EXP }}$ Average value of the pressing force [N]

$K$ Johanson's compressibility factor [1]

$M_{K}$ Torque on the compactor roll [Nm]

$R_{1} \quad$ Ratio of stress [1]

$V_{\theta} \quad$ Volume between arch length $\Delta L$ segments at position $\theta\left[\mathrm{m}^{3}\right]$

$V_{m}$ Volume at $\theta=0\left[\mathrm{~m}^{3}\right]$

$X$ Volume force in the plane $x[\mathrm{~N}]$

$X_{F}$ Force factor [1]
$Y \quad$ Volume force in the plane $y[\mathrm{~N}]$

$Y_{M}$ Torque factor [1]

\section{ACKNOWLEDGEMENTS}

This article was created with the support of the Ministry of Education, Science, Research and Sport of the Slovak Republic within the Research and Development Operational Programme for the project "University Science Park of STU Bratislava", ITMS 26240220084, co-funded by the European Regional Development Fund.

The authors wish to acknowledge the Scientific Grant Agency of the Ministry of Education, Science, Research and Sport of the Slovak Republic and the Slovak Academy of Sciences for the financial support of this research by grant VEGA 1/0276/17.

This article was created within the grant project "LISPRA" within the program of support for excellent teams of young researchers at the Slovak University of Technology in Bratislava.

This article was created within the grant project "SFEREX" within the program of support for team projects of young researchers at the Slovak University of Technology, Faculty of Mechanical Engineering.

\section{REFERENCES}

[1] J. R. Johanson. A rolling theory for granular solids. Journal of Applied Mechanics pp. 842-848, 1965.

[2] J. R. Johanson. Factors influencing the design of roll-type briquetting presses. Proceeding of 9-th Biennal Briquetting Conference 9:17-31, 1965. Denver, USA.

[3] J. R. Johanson. Feeding roll presses for stable roll operation. Proceeding of 18-th Biennial Conference of The Institute for Briquetting and Agglomeration 18:209-227, 1983. Colorado Springs, USA.

[4] J. R. Johanson. Fluid entrainment efects in roll press compaction. Powder Handling and Processing 2:183-185, 1989.

[5] J. R. Johanson. Reducing compacting roll wear through ecient roll face design and operating conditions. Proceeding of 16-th Biennial Conference of the Institute for Briquetting and Agglomeration 16:153-161, 1979. San Diego, Colorado, USA.

[6] J. R. Johanson. Reducing air entrainment problems in your roll press. Powder and Bulk Engineering 43, 1989.

[7] A. W. Jenike, R. T. Shield. On the plastic flow of coulomb solids beyond original failure. Journal of Applied Mechanics 26:599-602, 1959.

[8] M. Hubert. Application of compresibility equations in the theory of compactor design. Dissertations thesis. STU, Faculty of Mechanical Engineering, Bratislava, 2000. (In Slovak).

[9] M. Balicki. Numerical methods for predicting roll press powder compaction parameters. Centre Poudres Et Procédés, 2003.

[10] M. Hubert, A. Molnar, I. Jasso. Compressibility of particulate matter. Proceeding of 12th international Congress of Chemical and Process Engineering CHISA 12, 1996. Czech Republic. 
[11] A. Krok, R. Fekete, M. Peciar. Compaction of particulate material. STU, Bratislava, 2012. ISBN 978-80-227-3836-1. (In Slovak).

[12] P. Peciar, O. Macho, E. Eckert, et al. Modification of powder material by compaction processing. Acta Polytechnica 57 (2):116-124, 2017. ISSN 1805-2363.

[13] D. Geldart, E. Abdullah, A. Verlinden. Characterisation of dry powders. Powder Technology 190:70-74, 2009.

[14] U. Ulusoy, I. Kursun. Comparison of different 2d image analysis measurement techniques for the shape of talc particles produced by different media milling. Minerals Engineering 24:91-97, 2011.

[15] C. Vevoguer. Using laser diffraction to measure particle size and distribution. Metal Powder Report 68:15-18, 2013 .

[16] R. Freeman. Measuring the flow properties of consolidated, conditioned and aerated powders - a comparative study using a powder rheometer and a rotational shear cell. Powder Technology 174:25-33, 2007.

[17] R. Freeman, J. R. Cooke, L. Schneider. Measuring shear properties and normal stresses generated within a rotational shear cell for consolidated and non-consolidated powders. Powder Technology 190:65-69, 2009.

[18] L. Grossmann, J. Tomas, B. Csoke. Compressibility and flow properties of a cohesive limestone powder in a medium pressure range. Granullar Matter 6:103-109, 2004.

[19] G. Lumay, F. Boschini, K. Traina, et al. Measuring the flowing properties of powders and grains. Powder Technology 224:16-27, 2012.

[20] M. Peciar, R. Fekete, P. Peciar. Agglomeration technologies of processing powder wastes. Solid State Phenomena 244:121-129, 2016. ISSN 1012-0394.

[21] J. Úradníček, P. Kraus, M. Musil, M. Bachratý. Investigation of frictional stick-slick effect in disc brake nvh. Journal of Mechanical Engineering - Strojnicky časopis 67 (1):93-100, 2017. ISSN 2450-5471.

[22] J. Úradníček, P. Kraus, M. Musil. Investigation of frictional stick slip and sprag slip mechanisms leading to disc brake noise vibration and harshness effects. Aplimat 2017 16:1577-1585, 2017. ISBN 978-80-227-4650-2. 